\title{
ANALYSIS OF CRYOSCOPIC BEHAVIOUR OF DIESEL-BIODIESEL BLENDS USING INDUSTRIAL FREEZER
}

\author{
Marco Bietresato, Anna Bolla, Carlo Caligiuri, Massimiliano Renzi, Fabrizio Mazzetto \\ Libera Universita di Bolzano, Italy \\ marco.bietresato@unibz.it
}

\begin{abstract}
As opposed to gasoline, diesel oil has a lower limit temperature for its use in internal combustion engines (ICEs), which ranges between $-7{ }^{\circ} \mathrm{C}$ and $-20^{\circ} \mathrm{C}$ for the summer/winter formulation: it is therefore close to the average winter temperature typical of some European countries. In approaching such temperature, the formation of paraffins alters the physical characteristics of diesel oil (viscosity in particular) and makes it impossible to be used in ICEs. The same, aggravated problem is presented also by biodiesel and diesel-biodiesel blends, which are very interesting given their benefits in terms of performance and pollutant reduction in conventional compression-ignition engines (e.g., agricultural and operating machinery, cogeneration systems). Some varieties of biodiesel, such as biodiesel from palm oil, solidify at $13{ }^{\circ} \mathrm{C}$, whilst others, more suitable for winter temperatures, solidify at $-10{ }^{\circ} \mathrm{C}$ (biodiesel from canola seeds), which is nevertheless a higher temperature than that of diesel oil. In this work, a simple industrial freezer set at $-21^{\circ} \mathrm{C}$ was used to assess the freezing temperatures of many solutions of multiple components with different freezing points (diesel-biodiesel blends). The illustrated procedure use slow-cost and simple equipment thus allowing to reproduce similar experiments in industrial environments. The elaborations carried out have included the use of polynomial functions to fit the data and the identification of temperature tangency traits. Although the results are not in the form of the usual significant temperatures indicated by standards as cold-flow properties for fuels (i.e., pour point, cloud point, cold filter plugging point), they are substantially aligned with the literature data. However, the outcomes in the form of upper and lower liquid-to-solid temperatures are very interesting and useful to give the experimenters/users practical indications about the opportunity of using diesel-biodiesel blends with different compositions.
\end{abstract}

Keywords: biodiesel; biofuel blends; pour point; industrial freezer; freezing curves, binary phase diagram.

\section{Introduction}

Internal combustion engines, in particular compression-ignition (CI) engines, are to date one of the most versatile, reliable and widespread means of energy generation especially with regards to remote areas (e.g., agricultural landscapes) or where ease of access is limited (e.g., mountainous regions). Their compactness and torque curve make CI engines particularly suitable for heavy-duty tasks, e.g. in agricultural tractors, and for long-lasting applications as well, e.g. for cogeneration units [1]. In addition to these qualities, it is worth mentioning the possibility of CI engines being fuelled with biofuels without implementing major modifications to the power unit. Despite the recognized versatility of use of CI engines, there are some rather important limitations to the use of this type of engines, which must be ascribed to the liquid fuels adopted, both petro-diesel and biobased fuels.

Biofuels, with particular reference to second and third generation biofuels, could ensure high energy security and equity [2] and have a positive impact on environmental sustainability [3] due to the nature of their production technologies, their wide and diverse biological origins and their renewable nature. Several studies [4] affirm that biodiesel in particular has positive effects on exhaust emissions of CI engines: carbon monoxide (CO) is lowered, up to 30-50\% depending on the share of biodiesel in the blend [5], as well as hydrocarbons (HC) and particulate matter (PM). However, it is commonly recognized [6] that biodiesel properties bring in negative effects on nitrogen oxides $\left(\mathrm{NO}_{\mathrm{x}}\right)$ emissions, whose sensible relative increase represents one of the main drawbacks of using biodiesel as petro-diesel substitute [7]. Hence, CI engines emissions and performance are strongly affected by fuels properties that have a direct physical connection with the combustion process, such as viscosity, density, cetane number $(\mathrm{CN})$, and boiling point [6]. However, when dealing with operational limitations, other kind of considerations should be acknowledged, such as the effect on auxiliary organs. For example, several studies [8; 9] affirm that viscosity may reduce fuel flow rates, affecting the optimal functioning of the fuel feed pump. Another important limiting factor is represented by low temperatures [10], which can significantly affect some of the main physical properties of these fuels (specifically: the viscosity, the density, the fluidity) in such a way as to prevent their use in some periods of the year which vary with the latitude and/or the elevation. Indeed, diesel oil, diesel blended 
fuels and biofuels (e.g., biodiesel) can be classified based on a variety of properties, amongst which the cold-flow properties are the most relevant to determine the applicability of diesel in regions with low temperature ranges [11-13]. Cloud point (CP), pour point (PP), and cold filter plugging point (CFPP) are amongst the cold-flow properties generally investigated for fuels [14], and are respectively the specific temperature at which the aliphatic groups in fuels start to form solid crystals (waxes), where the fuel stops flowing [15; 16], and where the fuel is not able to flow through a filter in a certain time $[17 ; 18]$. International standards for the determination of these temperature points are, e.g. the American Society for Testing and Materials (ASTM [19]) standards, namely ASTM D2500 [20] for cloud point, ASTM D6371 [21] for cold filter plugging point, and ASTM D97 [22] for pour point. In Europe, the Deutsches Institut für Normung (DIN [23]) provides comparable, widely applied standards, such as EN 116:2015 for cold filter plugging point [24] or EN 23015:1994 [25] and ISO 3015:2019 [26] for cloud point. The procedures indicated in such standards are surely very precise, being mainly based on the direct observation of the first agglomerates of waxes, e.g. blocked by a filter, but require specific equipment for laboratory and trained personnel. Moreover, in recent years, many studies have demonstrated the extreme convenience in the use, in agricultural or cogeneration engines, of blends of two or three components at different percentages [27-29], each optimized according to the specific needs and to the engine in which they are used. Unfortunately, the actual freezing temperature of these blends is often not known, and this is a significant limitation in their use. Since the production of biodiesel can be obtained using different local wastes and resources and directly used in CI engines, a practical and simplified procedure to assess the basic fuel properties would be beneficial to deploy the use of such resources without relying exclusively on expensive and complex practices.

Therefore, the present study intends to investigate what information can be obtained by placing a sample of fuel or fuel blends under sub-freezing temperatures and by observing the temperature plots produced by temperature logging via thermocouples, which is a rapid and inexpensive approach to identifying the above-mentioned critical temperature points. The principle exploited is the change in the physical properties (in particular, the different specific heats) of the liquid and solid phases which results into different slopes of the temporal trends of the temperature. In this case, it is not possible to exploit the constancy of the temperature which otherwise occurs at phase changes in pure substances, since both diesel fuel and biodiesel are mixtures of several components and do not show such thermal behaviour. Other than demonstrating the overall viability of the method, this study will put at the reader's disposal some interpolation curves useful to estimate the freezing temperatures of dieselbiodiesel binary blends at any percentage of biodiesel.

\section{Materials and method}

The present investigation spans both an experimental and a data elaboration section. For the practical testing of temperature dependence, samples of fuel blends were subjected to freezing in a standard industrial freezer (Liebherr Comfort NoFrost CN 4815) at target temperature of $-21^{\circ} \mathrm{C}$. The fuel blends consisted of a combination of conventional diesel oil (D) and biodiesel (B) in varying volumetric proportions. According to [30], in Italy the $\mathrm{CP}$ for the pump summer diesel oil, like the one used in this investigation, is $-7 /+8^{\circ} \mathrm{C}$, and the CFPP $-17 /+2^{\circ} \mathrm{C}$. Please note that these values are quite different from those of the station winter diesel oil, due to some additives mixed in by the producer before selling the product on the market: $-12 /+6^{\circ} \mathrm{C}$ [30] or $-7 /-3^{\circ} \mathrm{C}[31]$ for the $\mathrm{CP},-29 /-3^{\circ} \mathrm{C}[30]$ or $-20 /-12^{\circ} \mathrm{C}$ [31] for the CFPP. The CP for the biodiesel used in this investigation is certified by the producer (EcoFox, Chieti, Italy [32]) at $13{ }^{\circ} \mathrm{C}$ and the CFPP at $10^{\circ} \mathrm{C}$. Table 1 reports the blends tested in the present investigation, together with pure diesel (D100, also called B0 to have a uniform indication based on the biodiesel percentage) and pure biodiesel (B100), for a total of 8 different fuels.

Table 1

Summary of the composition of the fuels/fuel blends tested in the current study

\begin{tabular}{|c|c|c|c|c|c|c|c|c|}
\hline \multirow{2}{*}{$\begin{array}{c}\text { Component, } \\
\% \text { v/v }\end{array}$} & \multicolumn{8}{|c|}{ Fuel } \\
\hline & B0 (D100) & B5 & B15 & B25 & B40 & B50 & B60 & B100 \\
\hline Diesel oil & 100 & 95 & 85 & 75 & 60 & 50 & 40 & 0 \\
\hline Biodiesel & 0 & 5 & 15 & 25 & 40 & 50 & 60 & 100 \\
\hline
\end{tabular}


One standard $50 \mathrm{~mL}$ laboratory Falcon tube was prepared for each test sample by boring a small hole into the cap (Fig. 1). $25 \mathrm{~mL}$ of each liquid was poured into the prepared Falcon tube, followed by the tightening of the screw cap. A T-type thermocouple compliant with IEC 584-2:1982 standard (temperature range: $-200 /+370{ }^{\circ} \mathrm{C}$; coupled materials: constantan, copper; accuracy: $\pm 0.5{ }^{\circ} \mathrm{C}$ ) was fitted into each of the prepared holes and carefully placed towards the centre of the liquid and against the bottom of the Falcon tube. All the samples were supported by a plastic rack. The rack, samples and thermocouples wires were placed inside the freezer with an additional thermocouple recording the air temperature inside the freezer chamber. Temperature of the samples was closely monitored for nearly 3 hours by taking a record every $10 \mathrm{~s}$ (i.e., the sampling frequency was set at $0.1 \mathrm{~Hz}$ ) using a DataTaker DT85M (by Thermo Fisher Scientific Australia Pty Ltd, Scoresby, Victoria, Australia [33]), able to automatically compensate the cold-junction.

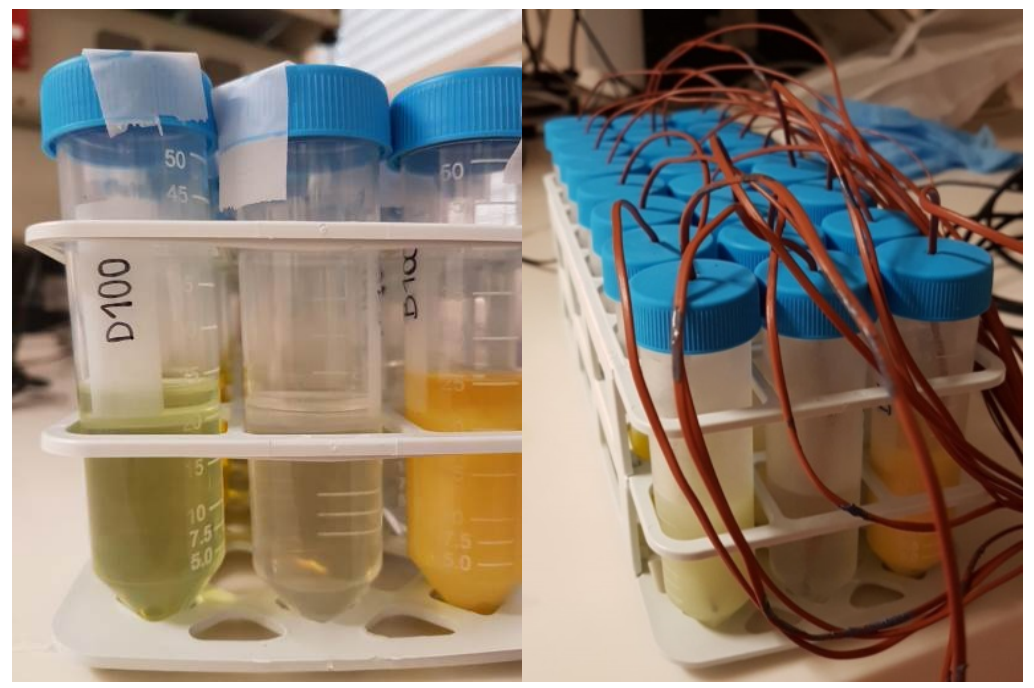

\section{Fig. 1. Preparation of the tube rack with the fuel blends to be frozen; the caps have been bored in the middle to insert a thermocouple in each tube}

Data analysis was carried out using a standard spreadsheet. After visual observation of the temperature data over time reported by the datalogger for the different blends, the following procedure was used to have more delineated trends (Fig. 2): a $4^{\text {th }}$-degree polynomial (trendline function of Microsoft Excel) for each blend was computed (Fig. 3). The degree of the interpolation polynomial was decided upon by observing the curve fit visually and through optimization of the reported $R^{2}$ (i.e., reaching the highest value of $\mathrm{R}^{2}$ with the lowest polynomial degree possible). Indeed, on the basis of the recorded trends, which were all very similar although differently positioned on the temperature scale, a $4^{\text {th }}$-degree polynomial proved to be the most suitable to fit the curves both in terms of capturing the macroscopic trend of the curves and in terms of the coefficient of determination $R^{2}$ (very high, for all greater than 0.957). Only this polynomial guaranteed a sufficiently-constant first derivative before and after the curved section connecting the two approximately-straight stretches during the phase transition. All observations concerning the trends of temperature over the time were formulated on the basis of these polynomial curves (and of their first derivatives when necessary) over the time interval between 720 and 2000 seconds, i.e. an approx. 8-minute interval at 12 minutes from the refrigeration start. Using tangent lines along the pseudo-straight stretches of the fitting curves, it has been possible to identify the start and end points of the curved stretches, corresponding to the progressive solidification of the considered blends (Fig. 3). Finally, a graph of the start and end temperatures of solidification of solutions as a function of the biodiesel content has been plotted. This graph is essentially a binary phase diagram, with the important difference that the mixed substances (diesel oil and biodiesel) are not pure substances. The data was analysed (1) both as the entire, raw dataset consisting of all temperature points (original database - OD), and (2) as a pre-processed dataset, reporting, instead of the original temperature data, the moving average calculated on 6 original temperature points, i.e. the average temperature on a minute (pre-processed database - PD). Thanks to the smoother trends assumed by the temperature curves after this latter operation, the individuation of the start and end transition points should in fact be easier. However, there is the risk of having slightly 
different values. Therefore, possible differences between these two slightly different procedures were brought to light.

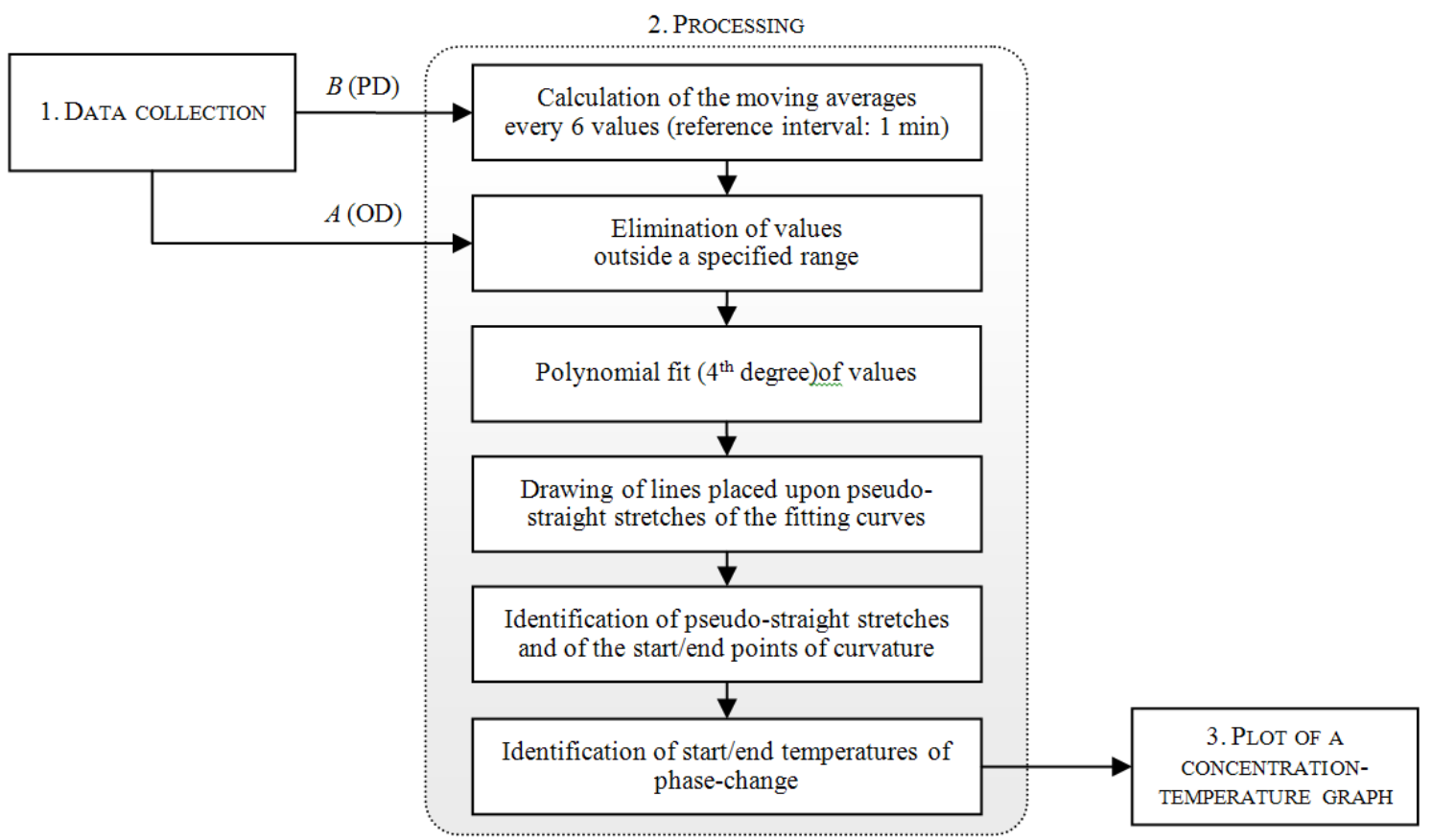

Fig. 2. Three-phase procedure followed to study the fuel blend solidification

(A) fit on original database; (B) fit on a pre-processed database

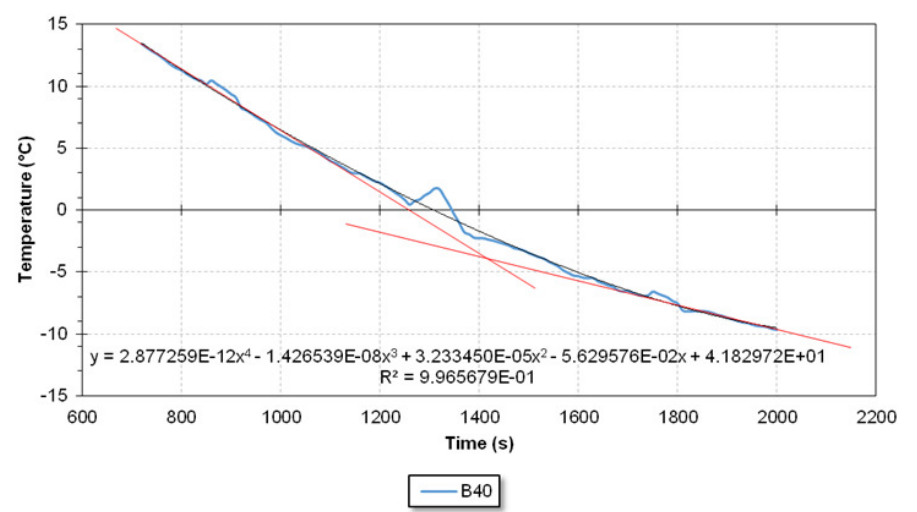

Fig. 3. Example of fitting of an experimental trend between 720 and $2000 \mathrm{~s}$ with a $4^{\text {th }}$-degree polynomial curve (B40); on the same graph the tangent lines are also traced

\section{Results and discussion}

The collected temperature data showed a decline in temperature for all fuel blends starting immediately after the door of the industrial freezer was closed (Fig. 4). The air temperature, which gives a baseline for observation within the freezer, shows a first sharp temperature decrease to $-10{ }^{\circ} \mathrm{C}$, followed by a rather slower descent to approximatively $-27^{\circ} \mathrm{C}$. Due to its lag, the successive temperature increases are linked to a systemic property of the freezer which halts the active refrigeration at certain intervals or after reaching certain low temperatures. In fact, once the air temperature reached $-10{ }^{\circ} \mathrm{C}$, the subsequent temperature descent followed a similar inclination as that previously displayed. Interestingly, this was not replicated fully between 6500 and $8000 \mathrm{~s}$. The small oscillations observable on all the temperature curves at 640,1310, 2890,4220, $5140,5990 \mathrm{~s}$ respectively are due to the acquisition system. Indeed, the same oscillations were detected on the fuel temperature curves without any delay with respect to the oscillation of the air temperature curve. However, it was decided to consider only the experimental points between 720 and $2000 \mathrm{~s}$, a period 
corresponding to a uniform and slow decrease in air temperature $\left(0.0047^{\circ} \mathrm{C} \cdot \mathrm{s}^{-1}\right.$, corresponding to $0.28{ }^{\circ} \mathrm{C} \cdot \mathrm{min}^{-1}$ ) and to the complete solidification of all samples.
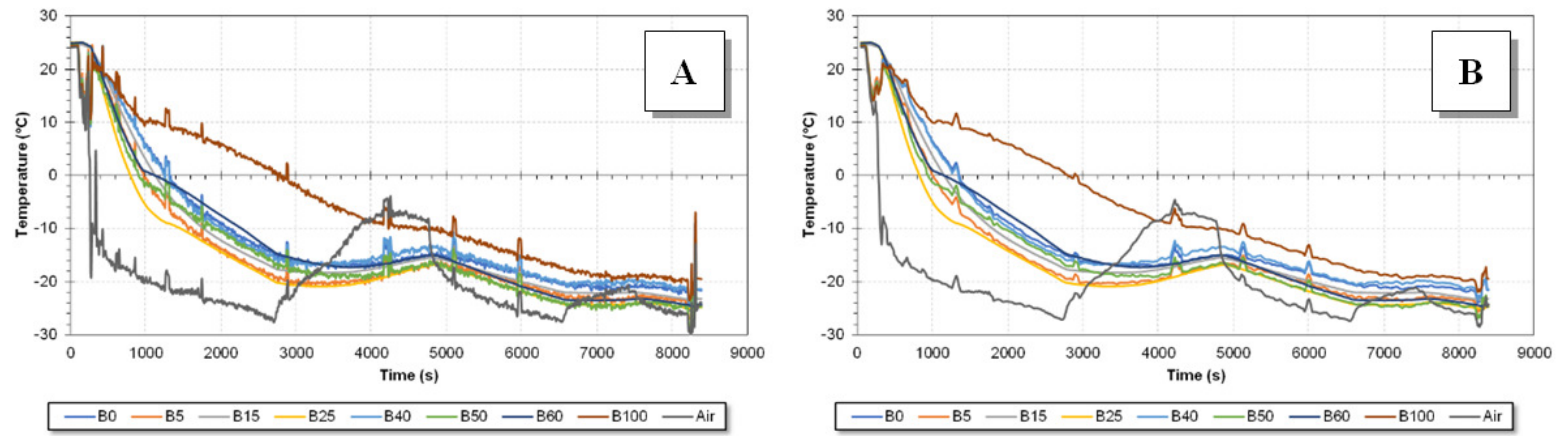

Fig. 4. Time-temperature trends for several fuel blends referred to the entire duration of the experiments: A - original database; $\mathrm{B}$ - pre-processed database (moving average on 6 values)

The behaviour of pure biodiesel (B100) was particular in that a seemingly slower temperature descent was observed compared to all other fuel blends (as visible in Fig. 5, the curve of pure biodiesel is above all other curves). In fact, a first point of inflection is observable for the B100 temperature descent already after approx. 15 minutes (precisely at $950 \mathrm{~s}$ ) and a second one at $1470 \mathrm{~s}$, corresponding respectively to the temperatures of $10.2^{\circ} \mathrm{C}$ and $8.9^{\circ} \mathrm{C}(\mathrm{OD})$ or $10.7^{\circ} \mathrm{C}$ and $8.8^{\circ} \mathrm{C}(\mathrm{PD})$, suggesting that a progressive degree of crystallization took place in the fuel between those two temperatures. The first temperatures are in accordance with the CFPP certified by the biodiesel producer $\left(10^{\circ} \mathrm{C}\right)$, the second ones can be probably next to the $\mathrm{PP}$, but this is actually impossible to verify (indeed the PP was not declared by the biodiesel producer). After that time interval, the temperature decrease of the B100 sample is substantially parallel to the temperature decrease recorded by the thermocouple exposed to the air, which could mean that no phase transition took place and that the sample is simply cooling in accordance with the refrigerator temperature. The behaviour of other fuels is very similar, with the curves very close one another although differently positioned in the Cartesian space (hence, with the slope changes occurring at different times and temperatures; Fig. 5). Also in these cases, the temperature trends reach the condition of parallelism with the air temperature trend after complete phase change.
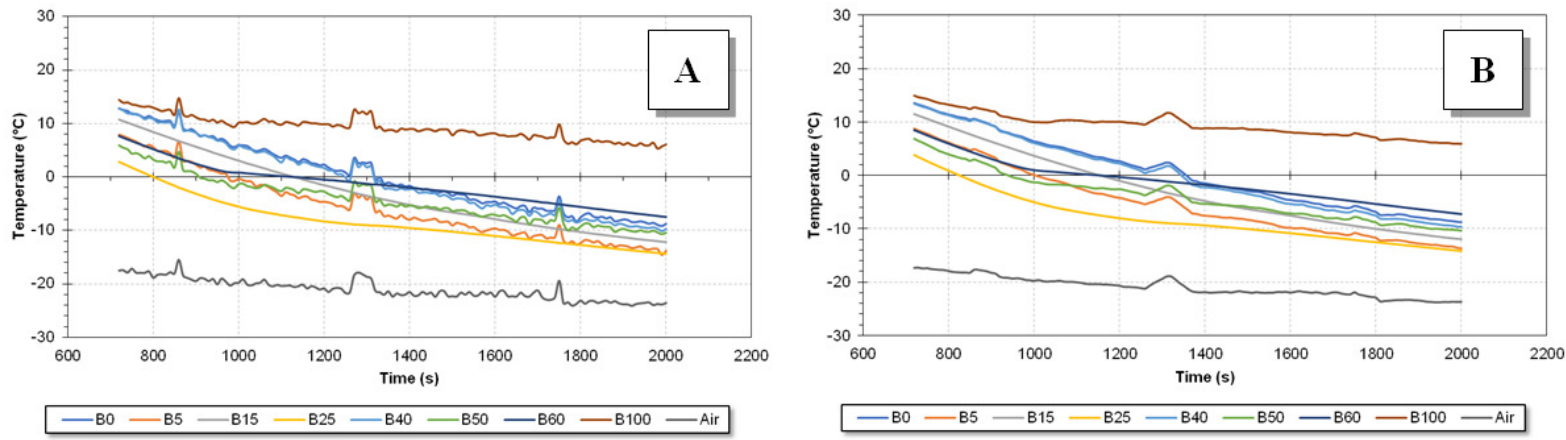

Fig. 5. Time-temperature trends for several fuel blends between 720 and 2000 s:

A - original database; B - pre-processed database (moving average on 6 values)

The temperatures of start and end of the liquid-to-solid phase transition on both the cases (OD, PD) are listed in Table 2; as visible, the differences between the start and end temperatures obtained from the two databases is of $0.6^{\circ} \mathrm{C}$ maximum, meaning that the two databases are substantially equivalent. By plotting the upper and lower temperatures as a function of the biodiesel concentration (Fig. 6), as previously explained, it is possible to obtain a graph that is very similar in its concept to a binary phase diagram. In this case, the mixed substances (diesel oil and biodiesel) are not pure substances, witnessed by the two phase-transition intervals at $0 \%$ and $100 \%$ (pure substances show a single phase-change temperature). The same graph shows that the phase transition interval of diesel fuel is much wider than that of biodiesel $\left(15.5^{\circ} \mathrm{C}\right.$ OD, $15.8^{\circ} \mathrm{C}$ PD vs. $1.3^{\circ} \mathrm{C} \mathrm{OD}, 1.9^{\circ} \mathrm{C}$ PD) and it decreases linearly as the percentage of biodiesel increases (see also Fig. 7). Although it is impossible to distinguish a CP or CFPP through this experiment, the temperatures obtained for the diesel oil and 
biodiesel are coherent with the range of values found in the literature for the diesel oil (i.e., $-17 /+8^{\circ} \mathrm{C}$ including the $\mathrm{CP}$ and CFPP ranges) or certified by the biodiesel producer (i.e., $+10 /+13^{\circ} \mathrm{C}$ including the $\mathrm{CP}$ and CFPP ranges). The trends in the upper/lower temperatures of the phase transition (i.e., the start/end temperatures if considering the freezing) individuate a scythe-shaped area on the graph, increasing as the biodiesel content increases. What emerges from this graph is that the addition of a minimum percentage of diesel oil to biodiesel, till reaching the volumetric concentration of $40 \%$ (i.e., obtaining a B60 blend), is sufficient to lower the upper phase transition temperature of about $4{ }^{\circ} \mathrm{C}$. Further additions of diesel oil have an effect mainly on the lower temperature of the phase change, which is lowered by about $20^{\circ} \mathrm{C}$ when raising the volumetric percentage of diesel oil from 0 to $100 \%$. In the same graphs of Fig. 6 the equations of the interpolating polynomials are also given; as visible, the determination coefficients $R^{2}$ are all very high ( $>0.966$ for the average phase-transition temperature), meaning that these equations can be reliably used to predict the temperature for binary blends having any concentration of biodiesel.

Summary of the freezing temperatures emerging from this study

Table 2

\begin{tabular}{|c|c|c|c|c|c|c|c|c|c|c|}
\hline \multirow{3}{*}{ Fuel } & \multirow{3}{*}{$\begin{array}{c}\text { Biod, } \\
\%\end{array}$} & \multicolumn{9}{|c|}{ Liquid-to-solid phase transition temperature $\left({ }^{\circ} \mathrm{C}\right)$} \\
\hline & & \multicolumn{4}{|c|}{ Original database } & \multicolumn{4}{|c|}{ Pre-processed database } & \multirow{2}{*}{$\begin{array}{l}\text { Diff. } \\
\text { Ave. }\end{array}$} \\
\hline & & Upper & Lower & Diff. & Ave. & Upper & Lower & Diff. & Ave. & \\
\hline B0 & 0 & +4.3 & -11.2 & +15.5 & -3.5 & +4.9 & -10.8 & +15.8 & -3.0 & +0.5 \\
\hline B5 & 5 & +1.3 & -7.7 & +9.0 & -3.2 & +2.2 & -7.4 & +9.7 & -2.6 & +0.6 \\
\hline B15 & 15 & +4.3 & -8.5 & +12.9 & -2.1 & +5.0 & -8.2 & +13.2 & -1.6 & +0.5 \\
\hline B25 & 25 & +0.4 & -9.0 & +9.4 & -4.3 & +1.2 & -8.9 & +10.1 & -3.8 & +0.5 \\
\hline B40 & 40 & +5.8 & -8.2 & +14.1 & -1.2 & +6.1 & -7.5 & +13.6 & -0.7 & +0.4 \\
\hline B50 & 50 & +3.9 & -2.7 & +6.6 & +0.6 & +4.3 & -2.6 & +6.8 & +0.8 & +0.3 \\
\hline B60 & 60 & +2.5 & -0.1 & +2.6 & +1.2 & +3.1 & +0.0 & +3.1 & +1.6 & +0.4 \\
\hline B100 & 100 & +10.2 & +8.9 & +1.3 & +9.5 & +10.7 & +8.8 & +1.9 & +9.7 & +0.2 \\
\hline
\end{tabular}
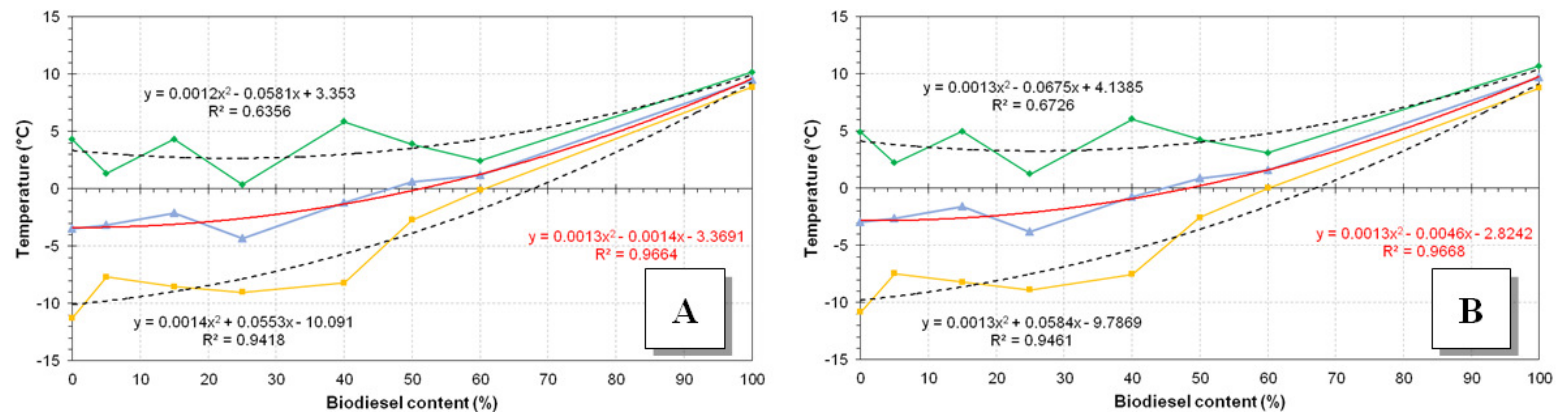

Fig.6. Phase-transition temperature (green broken line - upper temperature; blue - average temperature; orange - lower temperature) as a function of the biodiesel content: A - original database; B - pre-processed database (moving average on 6 values); smooth lines indicate the $2^{\text {nd }}$-degree interpolating polynomials ( $r e d$ for the average of upper and lower phase transition temperatures; black for both the upper and the lower phase transition temperatures)
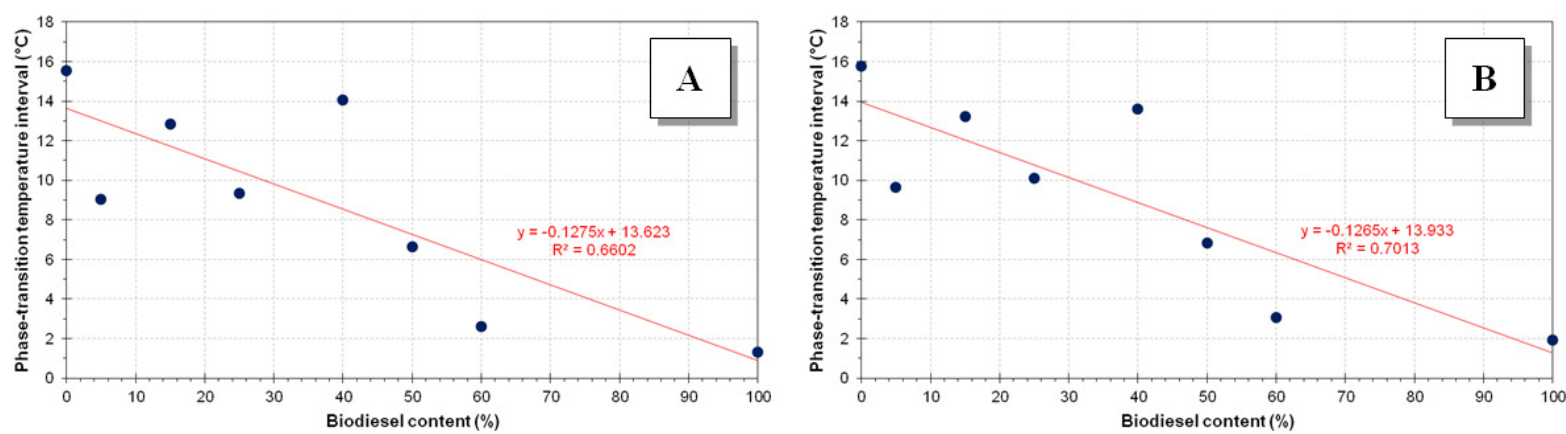

Fig. 7. Phase-transition temperature interval as a function of the biodiesel content:

A - original database; B - pre-processed database (moving average on 6 values) 
Finally, the estimations of the average temperatures for OD and PD, and of the temperature intervals for $\mathrm{OD}$ and $\mathrm{PD}$, have been plotted one against the other and the $R^{2}$ values have been calculated with reference to the bisector of the first and third quadrant (Fig. 8). For both the plots, the value of $\mathrm{R}^{2}$ is very high (respectively, 0.98842 for the temperatures and 0.98879 for the temperature intervals), indicating a very good coincidence of the evidences obtained with the two described procedures.
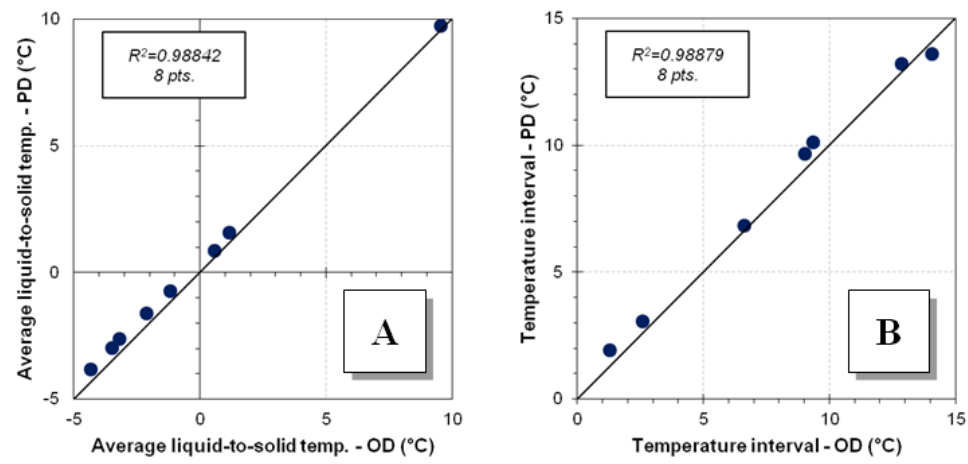

Fig. 8. Graphical comparison of (A) average liquid-to-solid temperatures and (B) phasetransition temperature intervals for the original and the pre-processed database (OD, PD)

\section{Conclusions}

The experimentation illustrated in this work showed a practical and simplified procedure to investigate the cryoscopic properties of diesel-biodiesel blends. Although the identification of the curve points of slope variation in the temperature graphs may not always be an easy task (it required fitting the data with $4^{\text {th }}$-degree polynomial functions and tracing of tangency lines), the results are certainly interesting. Indeed, at the end of the data processing step, it has been possible to build a binary phase diagram that is useful to estimate the start and end temperatures of phase transition at any percentage of biodiesel in the blend. The results are substantially aligned with the literature and the analysis reports for diesel and biodiesel, and show a phase transition field that is linearly narrowed as the biodiesel percentage increases. While the upper temperature has few changes up to $60 \%$ of biodiesel (an increase of about $6{ }^{\circ} \mathrm{C}$ can be observed), the greatest changes can be seen for the lower temperature, which varies instead of almost $20^{\circ} \mathrm{C}$. Finally, a comparison was also made between the results obtained by carrying out a database pre-processing operation (i.e., the calculation of the moving average on 6 subsequent values).The differences are not substantial and, therefore, this operation, useful for identifying the upper and lower temperatures, can be carried out without loss of information content.

\section{Acknowledgements}

This research was developed within the "VISCOMOTOR" ("Effects of biofuels on lubricants performance in internal combustion for agricultural purposes") internal research project, grant number TN200D. Moreover, the authors wish to thank Dr. Giovanni Pernigotto, for the useful suggestions, and Prof. Andrea Gasparella, for having put at the experimenters' disposal some of the used experimental instruments.

\section{References}

[1] Martinez S., Michaux G., Salagnac P., Bouvier J.L. Micro-combined heat and power systems (micro-CHP) based on renewable energy sources. Energy Convers Manag 2017; 154, pp. 262285. DOI: 10.1016/j.enconman.2017.10.035.

[2] EurObserv'ER. Biofuels Barometer. Le J Des Energies Renouvelables 2015.

[3] Rosegrant M.W., Zhu T., Msangi S., Sulser T. Global scenarios for biofuels: Impacts and implications. Rev Agric Econ 2008; 30, pp. 495-505. DOI: 10.1111/j.1467-9353.2008.00424.x.

[4] Suresh M., Jawahar C.P., Richard A. A review on biodiesel production, combustion, performance, and emission characteristics of non-edible oils in variable compression ratio diesel engine using biodiesel and its blends. Renew Sustain Energy Rev 2018; 92, pp. 38-49. 
DOI: 10.1016/J.RSER.2018.04.048.

[5] Lapuerta M., Armas O., Rodriguez-Fernandez J. Effect of biodiesel fuels on diesel engine emissions. Prog Energy Combust Sci 2008; 34, pp. 198-223. DOI: 10.1016/j.pecs.2007.07.001.

[6] Thangaraja J., Anand K., Mehta P.S. Biodiesel NOx penalty and control measures - a review. Renew Sustain Energy Rev 2016; 61, pp. 1-24. DOI: 10.1016/J.RSER.2016.03.017.

[7] Hazar H. Effects of biodiesel on a low heat loss diesel engine. Renew Energy 2009; 34, pp. 15331537. DOI: $10.1016 /$ j.renene.2008.11.008.

[8] Clenci A., Niculescu R., Danlos A., Iorga-Simăn V., Trică A. Impact of Biodiesel Blends and DiEthyl-Ether on the Cold Starting Performance of a Compression Ignition Engine. Energies 2016; 9, 284. DOI: 10.3390/en9040284.

[9] Caligiuri C., Bietresato M., Renzi M. The effect of using diesel-biodiesel-bioethanol blends on the fuel feed pump of a small-scale internal combustion engine. Energy Procedia 2019; 158, pp. 953958. DOI: 10.1016/j.egypro.2019.01.235.

[10] Speight J.G., Loyalka S.K. Handbook of Alternative Fuel 2007.

[11]Wang W., Li F., Li Y. Effect of biodiesel ester structure optimization on low temperature performance and oxidation stability. $\mathbf{J}$ Mater Res Technol 2020, pp. 1-10. DOI: $10.1016 /$ j.jmrt.2020.01.005.

[12] Lapuerta M., Rodríguez-Fernández J., Fernández-Rodríguez D., Patiño-Camino R. Cold flow and filterability properties of n-butanol and ethanol blends with diesel and biodiesel fuels. Fuel 2018; 224, pp. 552-559. DOI: 10.1016/j.fuel.2018.03.083.

[13] Silva P.H.R., Gonçalves V.L.C., Mota C.J.A. Glycerol acetals as anti-freezing additives for biodiesel. Bioresour Technol 2010; 101, pp. 6225-6229. DOI: 10.1016/j.biortech.2010.02.101.

[14] Knothe G., Krahl J., Van Gerpen J. The Biodiesel Handbook. vol. 1. 2005. DOI: $10.1201 / 9781439822357$.

[15] Coutinho J.A., Mirante F., Ribeiro J., Sansot J., Daridon J. Cloud and pour points in fuel blends. Fuel 2002; 81, pp. 963-967. DOI: 10.1016/S0016-2361(01)00213-7.

[16] Ribeiro N.M., Pinto A.C., Quintella C.M., da Rocha G.O., Teixeira L.S.G., Guarieiro L.L.N, et al. The Role of Additives for Diesel and Diesel Blended (Ethanol or Biodiesel) Fuels: A Review. Energy \& Fuels 2007; 21, pp. 2433-2445. DOI: 10.1021/ef070060r.

[17] Claudy P., Létoffé J-M., Bonardi B., Vassilakis D., Damin B. Interactions between n-alkanes and cloud point-cold filter plugging point depressants in a diesel fuel. A thermodynamic study. Fuel 1993, 72, pp. 821-827. DOI: 10.1016/0016-2361(93)90086-H.

[18] Mejía J.D., Salgado N., Orrego C.E. Effect of blends of Diesel and Palm-Castor biodiesels on viscosity, cloud point and flash point. Ind Crops Prod 2013; 43, pp. 791-797. DOI: 10.1016/j.indcrop.2012.08.026.

[19] ASTM International. ASTM International - Helping our world work better 2020. [online][25.03.2020] Available at: https://www.astm.org/

[20] ASTM International. ASTM D2500-17a, Standard Test Method for Cloud Point of Petroleum Products and Liquid Fuels. West Conshohocken, PA: 2017. DOI: 10.1520/D2500-17A.

[21] ASTM International. ASTM D6371-17a, Standard Test Method for Cold Filter Plugging Point of Diesel and Heating Fuels. West Conshohocken, PA: 2017. DOI: 10.1520/D6371-17A.

[22] ASTM International. ASTM D97-17b, Standard Test Method for Pour Point of Petroleum Products. West Conshohocken, PA: 2017. DOI: 10.1520/D0097-17B.

[23]DIN - Deutsches Institut für Normung. DIN Deutsches Institut für Normung 2020. [online][23.03.2020] Available at: https://www.din.de/en.

[24] Comité Européen De Normalisation. EN 116:2015 - Diesel and domestic heating fuels Determination of cold filter plugging point - Stepwise cooling bath method. 2015.

[25] Comité Européen De Normalisation. EN 23015:1994 - Petroleum products - Determination of cloud point. 1994.

[26] ISO - International Organization for Standardization. ISO 3015:2019 - Petroleum and related products from natural or synthetic sources - Determination of cloud point. 2019.

[27] Bietresato M., Caligiuri C., Bolla A., Renzi M., Mazzetto F. Proposal of a Predictive Mixed Experimental - Numerical Approach for Assessing the Performance of Farm Tractor Engines Fuelled with Diesel - Biodiesel-Bioethanol Blends. Energies 2019; 12, 2287. DOI: $10.3390 /$ en 12122287. 
[28] Caligiuri C., Renzi M., Bietresato M., Baratieri M. Experimental investigation on the effects of bioethanol addition in diesel-biodiesel blends on emissions and performances of a microcogeneration system. Energy Convers Manag 2019, pp. 55-65.

DOI: 10.1016/j.enconman.2019.01.097.

[29] Renzi M., Bietresato M., Mazzetto F. An experimental evaluation of the performance of a SI internal combustion engine for agricultural purposes fuelled with different bioethanol blends. Energy 2016; 115, pp. 1069-1080. DOI: 10.1016/j.energy.2016.09.050.

[30] Fiolet G., de las Heras R., Hoornaert P., Ingram M.S., Jörgensen R., De Vecchi G. A survey of european diesel fuel quality. Brussels, Belgium: 1995.

[31] Infineum International. Worldwide Winter Diesel Fuel Quality Survey 2016. 2016.

[32] Ecofox. Ecofox - Advanced Biofuels Producers \& Traders n.d. [online][23.03.2020] Available at: https://www.ecofox.eu/en/

[33] Thermo Fisher Scientific. Thermo Fisher Scientific 2015. [online][23.03.2020] Available at: https://www.thermofisher.com.au/ 